\title{
Solapamientos entre flexión y derivación: sobre la llamada derivación genérica en español
}

Petr Stehlík

Universidad Masaryk de Brno, República Checa

stehlik@phil.muni.cz

Trabajo recibido el 3 de mayo de 2018 y aprobado el 6 de agosto de 2018.

\begin{abstract}
Resumen
El presente artículo se ocupa del posible funcionamiento derivativo de los morfemas vocálicos - $o$ y $-a$, considerados tradicionalmente como desinencias de género, pero interpretados, en determinados usos (desde la moción de género en los nombres animados hasta la formación de sustantivos deverbales del tipo gasto, paga), como sufijos derivativos. Nuestro objetivo es demostrar, a través de un análisis detallado de las diferentes funciones que pueden desempeñar los morfemas en cuestión, que la diversidad de opiniones acerca de su carácter flexivo o derivativo refleja, en este caso, la existencia de una zona de transición entre la flexión y la derivación, cuyos grados igualmente tratamos de determinar.
\end{abstract}

\section{Overlaps between inflection and derivation: about the so-called gender derivation in Spanish}

\begin{abstract}
This article discusses the possible derivative functioning of the vocalic morphemes $-o$ and $-a$, traditionally considered as gender endings, but interpreted, in certain uses (from the gender inflection of animate nouns to the formation of deverbative nouns, such as gasto, paga), as derivative suffixes. Our objective is to demonstrate, through a detailed analysis of the different functions that can be performed by these morphemes in question, that the diversity of opinions about their inflectional or derivative nature reflects, in this case, the existence of a zone of transition between inflection and derivation, whose degrees we also attempt to determine.
\end{abstract}

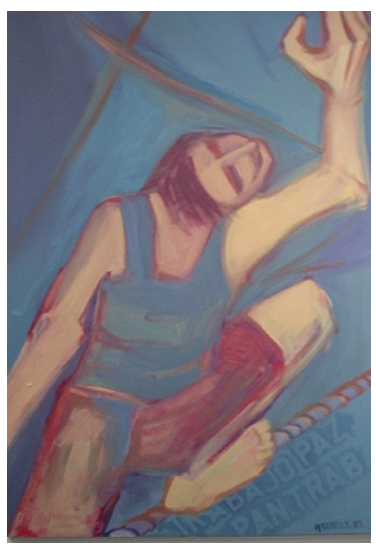

Palabras clave

español

formación de palabras desinencias de género función derivativa

Keywords

Spanish word formation gender endings derivative function 


\section{Sobreposições entre flexão e derivação: sobre a chamada derivação êricagenérica em espanhol}

\begin{abstract}
Resumo
Este artigo ocupa-se do possível funcionamento derivativo dos morfemas vocálicos - $o$ e - $a$, tradicionalmente considerados como desinências de gênero, mas interpretados, em determinados usos (desde a flexão de gênero nos nomes animados até a formação de substantivos deverbais do tipo gasto, paga) como sufixos derivativos. O nosso objetivo é demonstrar, através de uma análise detalhada das diferentes funções que os morfemas em questão podem desempenhar, que a diversidade de opiniões acerca do seu caráter flexivo ou derivativo reflete, neste caso, a existência de uma zona de transição entre a flexão e a derivação, cujos graus também tentamos determinar.
\end{abstract}

\section{Introducción ${ }^{1}$}

En principio, la división tradicional entre la morfología derivativa (o léxica) y la morfología flexiva parte de la premisa de que los afijos derivativos sirven para crear voces nuevas, en tanto que el uso de los morfemas flexivos, o desinencias, produce solo variaciones en palabras ya existentes "que implican cambios de contenido de naturaleza gramatical que tienen consecuencias en las relaciones sintácticas, como en la concordancia [...] o en la rección" (Real Academia Española y Asociación de Academias de la Lengua Española 2009, 21, en adelante NGLE; véase también Pena 1999, 4315). Aunque el objeto de estudio de la morfología léxica comprende, además de la derivación, también otros procedimientos de formación de palabras como son la composición y la parasíntesis, podemos decir que, al menos en español, el problema de la delimitación de las dos ramas de la morfología atañe exclusivamente a la sufijación derivativa frente a la flexión, con varias posibles áreas de transición. Si dejamos aparte el supuesto comportamiento semiflexivo de los sufijos apreciativos (Felíu 2009, 64-65; Aguirre 2013, 279), hipótesis que intentamos desbaratar en otro artículo nuestro (Stehlík 2017), esta zona de intersección abarca ante todo determinados usos del sufijo infinitivo -ar (p. ej.: limpio > limpiar; batalla > batallar) y de las desinencias de género - o y - $a$, cuyo funcionamiento derivativo examinaremos más detenidamente a continuación. Para ello, será de utilidad repasar primero las principales características que oponen los morfemas derivativos a los flexivos.

\section{Derivación vs. flexión: características diferenciadoras}

Aunque Rainer (1993, 37-40) enumera en su monografía 26 criterios de variada relevancia para delimitar los ámbitos de la derivación y la flexión, aquí vamos a enfocar solo aquellos rasgos distintivos que consideramos importantes para nuestro tema.

La diferencia fundamental, mencionada ya al comienzo de este artículo, al igual que en prácticamente todos los trabajos sobre formación de palabras, consiste en la capacidad neológica de los afijos derivativos. A pesar de parecer obvia, dicha característica tiene un papel clave en el posible análisis de las desinencias de género como elementos lexicogenéticos, según se verá sobre todo en el apartado 5.

\section{Palavras-chave}

espanhol

formação de palavras desinências de gênero função derivativa

1. Este artículo se basa parcialmente en una investigación más amplia cuyos resultados fueron publicados en el libro Problém delimitace některých slovotvorných postupůa prostředků ve španělštině (Stehlík 2016, disponible solo en checo). 
Otra propiedad exclusiva de los sufijos derivativos es su capacidad para cambiar la categoría gramatical de la palabra base, o sea, la llamada función transcategorizadora (de la cual, por cierto, carecen tanto los afijos flexivos como los apreciativos). También este criterio resulta importante, ya que explica por qué se analizan, casi unánimemente, las vocales finales $-o$, - $e$, - $a$ en los sustantivos deverbales (costar > costo, coste, costa) como morfemas derivativos con género masculino o femenino "inherente" (Santiago Lacuesta y Bustos Gisbert 1999, 4515, 4549 y 4584).

En cuanto al aspecto semántico de la derivación y la flexión, varios autores (Rainer 1993, 38; Aguirre 2013, 274) destacan el hecho de que los sufijos, en contraste con las desinencias, producen una modificación semántica más profunda de la palabra a la que se adjuntan y que el significado de la formación resultante es más imprevisible (o sea, menos transparente) que en el caso de las variaciones flexivas. La diversidad de usos de las terminaciones - $o$ y - $a$ (que sirven, además de especificar el sexo en los nombres animados, para establecer oposiciones del tipo grande/pequeño, árbol/fruto, etc.) muestra, sin embargo, que tampoco este criterio puede considerarse estrictamente binario.

Finalmente -y sobre todo por su validez cuestionable-, conviene mencionar la llamada relevancia sintáctica de los afijos flexivos frente a los morfemas derivativos. Por una parte, no se puede negar que

\footnotetext{
[l]a flexión es relevante para la sintaxis: esta característica se deriva del hecho de que los rasgos flexivos transmitan contenidos gramaticales, involucrados en procesos sintácticos como la concordancia o la rección (Varela 1990, 70).
}

Por otra parte, la afirmación de que los sufijos derivativos no son sintácticamente relevantes nos parece insostenible, ya que la capacidad transcategorizadora de la mayoría de los sufijos (analizarV > analizableA; fácilA $>$ fácilmenteAdv; acogerV > acogidaN) determina, sin lugar a dudas, las posibles funciones sintácticas de la palabra derivada. Y son precisamente los casos de la llamada derivación inmediata (gastar > gasto, m.; pagar $>$ pago, m., paga, f.) los que demuestran que el funcionamiento flexivo o derivativo de las terminaciones - $o$ y $-a$ no se excluyen mutuamente.

\section{Género gramatical y género natural}

Si dejamos a un lado la función sintáctica de las desinencias de género, estrechamente relacionada con el fenómeno de la concordancia (p. ej. entre el sustantivo y sus determinantes o modificadores) y utilizada ya por Nebrija ([1492] 1989, 187-188) para explicar la categoría de género ${ }^{2}$, podemos decir, siguiendo a Pena $(1999,4322)$, que la función de las terminaciones -o y - $a$ es "simplemente clasificadora [...] en los sustantivos de género fijo tipo casa, libro", donde los morfemas en cuestión — de carácter flexivo incontestable ${ }^{3}$ - no hacen más que manifestar formalmente el género inherente del nombre, sin aportar rasgo semántico alguno ${ }^{4}$.

La situación se complica en el caso de los nombres animados del tipo niño/niña, en los que la desinencia de género, además de cumplir la función arriba mencionada, expresa también el género natural (macho/ hembra), o sea, una oposición que radica en la realidad extralingüística y que, desde cierto punto de vista, podría interpretarse como significado
2. La definición del género gramatical que ofrece la NGLE $(2009,81)$ es también sintáctica: “El género es una propiedad de los nombres y de los pronombres que tiene carácter inherente y produce efectos en la concordancia con los determinantes, los cuantificadores, los adjetivos y, a veces, con otras clases de palabras".

3. Sin embargo, Ambadiang (1999, 4872) menciona en su estudio también una concepción más restrictiva del género gramatical, según la cual "las desinencias - $a$, -o y, en menor medida, - e pueden tener el estatuto de morfema de género sólo en los nombres que admiten el desdoblamiento genérico (hermano/hermana, monje/monja, zorro/zorra), puesto que, a pesar de su similitud con las marcas canónicas de género y de su correlación con los rasgos de género, las vocales finales de los nombres que no entran en tales oposiciones son descritas como simples fonemas (cf. libro, libra, puerto, puerta, etc.)".

4. En contraste con los sustantivos inanimados que serán comentados en el apartado 4. 
léxico (aunque categorial, lo que no supone ninguna contradicción). A este respecto, las opiniones de los lingüistas difieren ya considerablemente. Mientras que los gramáticos españoles contemporáneos son, en general, bastante reacios a ver en la moción de género en los sustantivos animados (niño/niña) un proceso diferente de la mera variación flexiva ${ }^{5}$, algunos hispanistas extranjeros consideran este mecanismo como un tipo de derivación (Lang 1992, 245-247; Rainer 1993, 96; Lüdtke 2011, 77). Conviene agregar que Lang (1992), a pesar de tratar la moción de género en el subcapítulo titulado Derivación genérica, probablemente no estaba del todo convencido del carácter derivativo del mecanismo en cuestión, ya que no lo incluyó en ninguno de los dos capítulos dedicados a la sufijación (cap. 4 y 5), sino entre los llamados Procedimientos misceláneos (cap. 9).

En lo que se refiere a los morfólogos españoles, hay que constatar que varios autores de tratados sobre formación de palabras (Alvar Ezquerra 1993, Miranda 1994, Almela 1999) pasaron completamente por alto este problema teórico. No así Pena (1999, 4322-4323), quien se ocupa detalladamente en la Gramática descriptiva de la lengua española (en adelante GDLE) de las diversas funciones semánticas de las vocales finales -o y - $a$, y apunta que el género en los nombres animados "tiene [...] función representativa, marcando la diferencia de sexo" (Pena 1999, 4322); algo que, obviamente, sobrepasa el ámbito de lo puramente lingüístico o gramatical. Además, la lengua española dispone de otros recursos para expresar el género natural, entre ellos algunos sufijos estándar (gallo $>$ gallina; poeta > poetisa) de cuyo estatuto derivativo no hay ninguna duda. En cualquier caso, ni siquiera Pena defiende el estatuto derivativo de las desinencias de género en ningún uso particular. Lo mismo puede decirse de la NGLE (2009), en la que, sin embargo, encontramos un párrafo extenso dedicado a la crítica de la tradicional inclinación "por asociar el género con la vocal -o que caracteriza a los sustantivos masculinos (tiempo, huerto) y con la vocal -a que identifica a los femeninos (casa, huerta)" (NGLE 2009, 90).

En contraste con ello, Serrano-Dolader $(2010,14)$ afirma que "[d]esde el punto de vista formal, la flexión de género prototípica presenta en oposición las marcas flexivas de $-o$ / $-a^{\prime \prime}$, y determina como función prototípica de las desinencias de género la de diferenciar el sexo de los seres animados.

Si bien Fábregas (2013, 211-212) aborda en su libro solo la variante derivativa de la moción (p. ej.: alcalde > alcaldesa; sacerdote > sacerdotisa) para reflexionar sobre la naturaleza de los sufijos -esa, -isa en los ejemplos citados, su mención circunstancial (Fábregas 2013, 212) de que el nombre alcaldesa se refería originalmente a la esposa del alcalde nos lleva al verdadero punto de transición entre los usos flexivos y derivativos de las desinencias de género.

En las palabras como generala, coronela, etc., la marca del femenino ya no se limita a indicar el género gramatical y natural de los nombres animados (como en hijo/hija, niño/niña), sino que sirve, simultáneamente, para relacionar el estatuto social de la mujer con el cargo de su marido ("mujer del general", "mujer del coronel"; Diccionario de la lengua española 2017, en adelante DLE). Está claro que este uso (minoritario y más bien anticuado) de la vocal final - a sobrepasa los límites de la flexión, pues mantener que el significado 'esposa de' es gramatical o categorial rozaría ya lo absurdo.
5. Al contrario de lo que pudiera parecer, esta postura no refleja la tradición lingüística española, mantenida, paradójicamente, por la mayoría de los lingüistas extranjeros incluidos en nuestra bibliografía (véase más adelante). Margarita Lliteras, quien hizo un análisis historiográfico del concepto de género gramatical en español (2008), muestra con abundantes citas que hasta la primera mitad del siglo XX "debió de predominar el criterio tradicional basado en el carácter invariable del sustantivo a la flexión de género, salvo quizá en el grupo reducido de los nombres de parentesco. Los autores atribuían a la derivación el cambio del masculino al femenino o bien a la lexicalización de adjetivos, estos sí, de género variable" (Lliteras 2008, 135). Obsérvese que esta tradición podría también explicar la ambigüedad que caracteriza la descripción de la derivación nominal deverbal en autores clásicos como Alemany Bolufer (1920) y que comentamos en el apartado 5 (véase la nota a pie 7). 


\section{Otras oposiciones semánticas expresadas mediante las terminaciones $-0,-a$}

A diferencia de lo comentado en el apartado anterior, la relación entre el género gramatical y el natural se rompe totalmente en el caso de algunos sustantivos inanimados cuya forma del masculino o femenino sirve para establecer oposiciones diversas (aunque no siempre completamente regulares): contable/incontable (leño/leña), árbol/fruto (manzano/manzana), grande/pequeño (barco/barca), etc. (véase NGLE 2009, 91-92; Ambadiang 1999, 4882).

Volviendo a nuestra contrastación de las opiniones de morfólogos españoles y extranjeros, conviene empezar por Lang (1992, 247-248), quien sitúa los usos de las desinencias -o y - $a$ arriba señalados (al igual que la moción de género en los sustantivos animados) en el campo de la llamada derivación genérica. Al comparar parejas de nombres como cereza/cerezo, almendra/ almendro con melocotón/melocotonero, pera/peral, etc., el lingüista inglés apunta lo siguiente:

$[P]$ arece que la alternancia morfológica [a]/[o] en el léxico agrícola puede tener la misma función que el sufijo estándar, al derivar el nombre del árbol desde la fruta o planta. Esta función semántica puede comprobarse como coincidente con la derivación (Lang 1992, 248).

Rainer (1993) deja esta cuestión sin comentario, mientras que Lüdtke (2011, 78, nota 74) opina que al menos algunos nombres de frutas y seres animados fueron utilizados, de manera atestiguada (a diferencia de las "palabras de transmisión popular"), como base para modificaciones morfológicas de carácter derivativo: guayaba > guayabo; papaya > papayo; cacique > cacica.

Si, según hemos visto, en los estudios escritos por romanistas extranjeros predomina la tendencia a interpretar este funcionamiento específico de las desinencias - o y - $a$ del mismo modo que la moción de género en los nombres animados, algo semejante (pero con respecto a otra postura) puede decirse de lingüistas españoles como Alvar Ezquerra (1993), Miranda (1994) o Almela (1999), para quienes ni la especificación de sexo, ni la manifestación de otras oposiciones semánticas mediante los morfemas - o y - a parecen sobrepasar los límites de la flexión. Más recientemente, sin embargo, Aguirre (2013, 273) reconoce, al comentar la relación entre palabras como bolso/bolsa, barco/ barca, anillo/anilla, que "[e]n todos estos casos, la diferenciación de género se está utilizando para crear nuevos significados", y llega a afirmar que "la marca flexiva de género se está comportando aquí como un verdadero sufijo derivativo, en el sentido de que está creando palabras nuevas".

Serrano-Dolader (2010), a su vez, considera los usos de las desinencias de género para especificar el sexo de los seres animados y para marcar la oposición árbol/fruto como

los extremos de la relación de continuum que manifiesta el género en los sustantivos españoles: por una parte las parejas del tipo niño/niña se acomodan perfectamente a la caracterización de la flexión; por otra parte, el contraste manzana/manzano resulta de la aplicación de procesos derivativos (Serrano-Dolader 2010, 17).

Cabe precisar que el autor citado analiza las vocales finales - o y - $a$ en el último ejemplo como marcas derivativas "simplemente homónimas a las 
marcas flexivas de género -o, - $a$ en chico/chica" (Serrano-Dolader 2010, 15), esgrimiendo, entre otros argumentos, que la orientación derivativa unidireccional en los pares de nombres como manzana/manzano, cereza/ cerezo (femenino > masculino) es inversa a la orientación genérica que caracteriza la moción (masculino > femenino). En contra de la homonimia de los morfemas en cuestión puede aducirse, sin embargo, que incluso en cuanto sufijos derivativos, las terminaciones $-o$ y $-a$ siguen cumpliendo su función básica de marcas flexivas, a saber, la de manifestar el género formal del nombre.

\section{Las vocales finales $-0,-e,-a$ en los sustantivos deverbales}

En la tradición gramatical española (Menéndez Pidal 1918, Alemany Bolufer 1920; más recientemente también Alvar Ezquerra 1993), la formación de palabras mediante la adición de una desinencia de género ${ }^{6} \mathrm{o}$ infinitivo a la base léxica (igualA > igualarV; fusilN > fusilarV; pagarV > pagoN, paga $\mathrm{N}$ ) suele designarse con el término derivación inmediata o impropia, pues aunque el sufijo empleado es, en principio, flexivo, su aplicación produce la llamada metábasis (cambio categorial de la base), considerada como uno de los rasgos más importantes que diferencian la derivación de la flexión.

Para resolver esta aparente contradicción, la mayoría de los lingüistas españoles (Almela 1999, Santiago Lacuesta y Bustos Gisbert 1999, Varela 2005, NGLE 2009) optaron por reconocer a las vocales finales $-o$, $-e$ y $-a$ con función nominalizadora (y unidas a la raíz verbal sin la vocal temática, p. ej.: pag(a)-o) el estatuto de morfema derivativo ${ }^{7}$, algo que —como en la propuesta de Serrano-Dolader arriba comentada-sugiere su mera homonimia con las desinencias de género. Sin embargo, la solución que acabamos de exponer no es la única alternativa a la derivación inmediata, porque Rainer (1993, 382), quien coincide en este caso con los morfólogos españoles, describe en su libro otros tres posibles análisis de los sustantivos deverbales.

Empezando por la alternativa más improbable, los nombres como pago, paga se corresponderían con determinadas formas finitas del verbo en cuestión (p. ej.: paga = 3a persona del sg. del presente de indicativo), transformadas en sustantivos mediante el mecanismo de conversión.

Otro análisis, también bastante especulativo, recurre al concepto de sufijo cero, el "verdadero" responsable de la derivación nominal a la que seguiría, como mera consecuencia de la recategorización ya efectuada, el proceso de asignación del género gramatical (es decir, pag-ø-o). Pero, en tal caso, ¿cómo explicar el género masculino inherente de la vocal final -e (coste, m.; desgaste, m.), ambigua al respecto fuera de este uso particular? ${ }^{8}$

Finalmente, la formación de nombres deverbales con los sufijos - $o$, - $e$ y - $a$ puede interpretarse, según Rainer $(1993,382)$, como la adición de un morfema derivativo a la forma infinitiva del verbo sin la desinencia -ar (pag(ar)-o). Según se ve, la diferencia entre este análisis y el preferido por la mayoría de los morfólogos españoles (a saber, pag(a)-o) concierne a la segmentación de la base verbal, sin que ello afecte el carácter derivativo del proceso lexicogenético en sí.
6. Pero véase la nota a pie 5 .

7. Curiosamente, ya en el primer tratado de la formación de palabras en español encabezan la lista de los "sufijos que en la derivación nominal emplea la lengua castellana" (Alemany Bolufer 1920, 3-4) los morfemas - $a$, -e, $-o$, sin que haya allí mención alguna sobre el posible carácter flexivo de los mismos. No obstante, en otro lugar leemos también que "[l]a derivación verbal puede ser, como la nominal, inmediata o primaria y mediata o secundaria" (Alemany Bolufer 1920, 136), lo que nos hace reconsiderar la aparente modernidad del análisis de los nombres deverbales en el trabajo citado.

8. Compárense p. ej. coste, m., desgaste, m. con monte, $\mathrm{m}$., variante, f., padre, m., madre, f., etc. 
En cualquier caso, la diversidad de opiniones al respecto es aún mayor. Lang (1992, 193-196) considera la formación de nombres deverbales/postverbales como un tipo especial de la sufijación no apreciativa (derivación regresiva), dado que

[e]l resultado de este tipo de derivación es inferior en cuanto al número de sílabas que presentaba la base, cuando, habitualmente, la sufijación lo que produce es un aumento silábico de la misma (Lang 1992, 193).

También Almela (1999, 199-202) trata sobre este proceso morfológico en el subcapítulo Regresión (pero dentro del capítulo Otros procedimientos) y utiliza los términos alternativos derivación regresiva y derivación postverbal ${ }^{9}$. Sin embargo, su descripción del propio mecanismo, citada a continuación, se asemeja sospechosamente a la definición de la derivación inmediata ${ }^{10}$ y puede hacer dudar al lector sobre el carácter derivativo o flexivo del morfema final: "El modelo más común en español [...] se presenta como la sustitución de las terminaciones de infinitivo (-ar, -er, -ir) por las terminaciones $-a,-e,-o,-e o,-\varnothing "$ (Almela 1999, 200). Esta formulación es ambigua, pero tomando en consideración que Almela $(1999,108)$ incluye los morfemas - $a,-e,-o$ en su tabla completa de los sufijos del español (entre los sufijos exocéntricos sustantivadores y con algunos ejemplos que aparecen igualmente en el subcapítulo Regresión, como probar > prueba; reñir $>$ riñ ${ }^{11}$ ), creemos que es legítimo señalar a este lingüista como representante del tercer análisis alternativo (es decir, pag(ar)-o).

Nos queda por mencionar la postura minoritaria de Lüdtke (2011, 187-188), según el cual la formación de sustantivos deverbales que implica el uso de los morfemas - $O,-e,-a$ supone un procedimiento de "conversión con cambio de paradigma" (Lüdtke 2011, 187), o sea, uno de los tipos de la llamada transposición. Cabe observar que esta interpretación se diferencia del concepto tradicional de la derivación inmediata "solo" por el hecho de que en la conversión -y también en la supuesta derivación deverbal mediante sufijo cero-, la aplicación del afijo flexivo no es causa sino consecuencia (aunque no indispensable, como podemos ver en el ejemplo deslizarV $>$ deslizN) del cambio categorial, mientras que los defensores de la derivación inmediata asignan la función transcategorizadora precisamente a la terminación.

El problema común de todos los análisis que coinciden en mantener el carácter flexivo de las vocales finales $-o,-e,-a$ en sustantivos como costo, coste, costa es, en nuestra opinión, la inexplicable -o no satisfactoriamente explicada- regularidad con la que el morfema -e impone al nombre deverbal el género masculino, a pesar de carecer de semejante univocidad en cualquier otro grupo de sustantivos. Por otra parte, si los sufijos en cuestión son morfemas derivativos con género inherente, según se afirma en la mayoría de los trabajos recientes, se plantea la pregunta de cuál es la aportación de los sufijos $-o,-a$, - e al significado típico de los nombres deverbales ('acción y efecto'; véase, entre otros, NGLE 2009, 380-381), que resulta, sin más, del origen verbal de estas formaciones, tal y como se comprueba en los derivados con sufijo cero (desliz = "acción y efecto de deslizar o deslizarse"; perdón = "acción de perdonar"; DLE 2017). En vista de lo anterior, Lang puede tener razón cuando constata que

este procedimiento muestra coincidencias evidentes entre flexión y derivación, debido a que los morfemas implicados son los que habitualmente se utilizan como marcas de género o de paradigma verbal (Lang 1992, 195-196).
9. En este contexto conviene mencionar la crítica de Serrano-Dolader (1994) a los términos nombre deverbal/ postverbal y derivación deverbal/ postverbal/regresiva. Según advierte el autor (Serrano-Dolader 1994, 283), "el basarse en dataciones referidas a la fecha inicial de atestiguación de las unidades léxicas que se estudian, como argumento fundamental para marcar la "dirección» de la derivación entre parejas de verbos y sustantivos corradicales, no se corresponde con las exigencias metodológicas de un análisis estrictamente sincrónico de los procesos morfológicos". Sincrónicamente, no se trata de una relación "de dependencia, sino de coexistencia asociativa entre el verbo y el sustantivo" (SerranoDolader 1994, 284). Por ello resulta más correcto hablar, refiriéndose a los sustantivos del tipo costo, coste, costa, de "nombres verbales con sufijo átono" (Serrano-Dolader 1994, 285). 10. Véase el comienzo del presente apartado.

11. Compárense las páginas 108 y 200 de Almela (1999). 


\section{Conclusiones: Gradualidad de las funciones de los morfemas -o, -a}

En los apartados 3 a 5 hemos intentado abarcar la amplia gama de usos que tienen los afijos - $o$ y - $a$ en el sistema nominal, esforzándonos por explicar las líneas de razonamiento que dan pie a interpretaciones muy divergentes planteadas por renombrados lingüistas tanto españoles como extranjeros. Partiendo del hecho de que "no existe una brecha limpia" entre la flexión y la derivación y que "[l]a diferencia está en el grado, más que en otra cosa" (Varela 1988, 515), podemos aventurarnos a afirmar que la diversidad de opiniones acerca del funcionamiento derivativo o flexivo de las vocales finales - $o$ y - $a$ corrobora la existencia de una escala cuyos extremos son la flexión y la derivación, y cuya gradualidad se ve claramente en la siguiente tabla:

\begin{tabular}{|l|l|l|}
\hline \multicolumn{2}{|l|}{ Funciones de los morfemas vocálicos -o, -a en el sistema nominal } \\
\hline \multirow{5}{*}{ Flexión } & $\begin{array}{l}\text { 1. Género gramatical } \\
\text { (nombres inanimados: libro, mesa) }\end{array}$ & Función clasificadora (m./f.) \\
\cline { 2 - 3 } & $\begin{array}{l}\text { 2. Género natural } \\
\text { (nombres animados: niño/niña) }\end{array}$ & $\begin{array}{l}\text { Función clasificadora (m./f.) } \\
\text { Oposición de sexo }\end{array}$ \\
\cline { 2 - 3 } & $\begin{array}{l}\text { 3. Significado ,esposa de، } \\
\text { (nombres de cargos: generala, coronela) }\end{array}$ & $\begin{array}{l}\text { Función clasificadora (f.) } \\
\text { Rasgo semántico 'hembra' } \\
\text { Rasgo semántico 'esposa de' }\end{array}$ \\
\cline { 2 - 3 } Derivación & $\begin{array}{l}\text { 4. Otras funciones semánticas } \\
\text { (manzano/manzana, barco/barca) }\end{array}$ & $\begin{array}{l}\text { Función clasificadora (m./f.) } \\
\text { Relaciones semánticas diversas } \\
\text { (árbol/fruto, tamaño, etc.) }\end{array}$ \\
\cline { 2 - 3 } & $\begin{array}{l}\text { 5. Formación de nombres deverbales } \\
\text { (gasto, paga) }\end{array}$ & $\begin{array}{l}\text { Función clasificadora (m./f.) } \\
\text { Función transcategorizadora }\end{array}$ \\
\hline
\end{tabular}

Tabla 1: Gradualidad de las funciones de los morfemas vocálicos -0, -a.

1) En los nombres inaminados cuyo género resulta formal y fijo (libro, mesa), las vocales finales - $o$ y - $a$ desempeñan una función meramente clasificadora $\mathrm{y}$, como tal, puramente gramatical.

2) La moción de género en los nombres animados (niño/niña, chico/chica, etc.) supone el primer paso en dirección a la función derivativa de los morfemas $-o,-a$, ya que el género gramatical coincide aquí con la expresión del género natural (es decir, la diferencia de sexo en los seres animados), sobrepasando así el ámbito de la gramática.

3) Si la oposición macho/hembra puede aún interpretarse como categorial o general (y, por ello, gramatical), en el caso de formas como generala, coronela, etc. - donde la vocal final - $a$, aparte de indicar el género gramatical y el natural, adquiere el significado específico de 'esposa de'- resulta ya realmente difícil defender que estamos ante meras variantes flexivas de género. Aunque casi ninguno de los autores de nuestra bibliografía presta atención a este uso particular de la terminación - $a$, por razones arriba expuestas consideramos legítimo señalarlo como limítrofe entre la flexión y la derivación.

4) El empleo de los sufijos vocálicos -o y - $a$ para marcar relaciones semánticas de diversa índole entre algunos nombres inanimados (barco/barca, leño/leña, manzano/manzana) representa, en nuestro esquema, otro grado de transición desde la flexión hacia la derivación. Por un lado, los morfemas en cuestión desempeñan en estas palabras el papel básico de las desinencias de género, es decir, el de indicar y determinar el género formal de los sustantivos acabados en una vocal átona (como en los puntos 1 a 3); pero, por otro lado, su aportación sémica carece de cualquier conexión con la oposición de género natural, prototípica de las desinencias de género desde el punto de vista semántico. 
5) En la propuesta de Serrano-Dolader (2010) está ejemplificado el extremo opuesto al funcionamiento prototípicamente flexivo de los morfemas de género por la pareja manzano/manzana, comentada ya en el punto anterior. Sin embargo, si aceptamos la postura mayoritaria de los gramáticos españoles de que la formación de sustantivos deverbales del tipo pago, paga supone un proceso derivativo acompañado por la asignación del género en función del sufijo vocálico empleado, podemos sostener que es precisamente este uso de las terminaciones - $o$ y - $a$ el que más cumple con las principales características de la sufijación derivativa, pues implica también el cambio categorial de la palabra base.

A modo de conclusión, cabe recalcar que la precariedad de los límites entre la flexión y la derivación no es una cuestión meramente académica o teórica, porque concierne a la interpretación de algunos fenómenos morfológicos muy concretos, siendo tal vez el mejor ejemplo de ello el funcionamiento de los sufijos vocálicos -o y - $a$ dentro del sistema nominal. A lo largo de estas páginas hemos tratado de demostrar que la discrepancia de los gramáticos en cuanto al carácter flexivo o derivativo de dichos morfemas no se debe solo a enfoques teóricos diferentes o, tal vez, a preferencias subjetivas de ciertos lingüistas, sino - y sobre todo- a la existencia de una zona de transición gradual entre la flexión y la derivación, imposible de ser satisfactoriamente descrita en términos binarios. 


\section{Q Bibliografía}

»Aguirre, Carmen. 2013. Manual de morfología del español. Barcelona: Castalia.

»Alemany Bolufer, José. 1920. Tratado de la formación de palabras en la lengua castellana: La derivación y la composición. Madrid: Victoriano Suárez.

»Almela Pérez, Ramón. 1999. Procedimientos de formación de palabras en español. Barcelona: Ariel.

» Alvar Ezquerra, Manuel. 1993. La formación de palabras en español. Madrid: Arco/Libros.

» Ambadiang, Théophile. 1999. “La flexión nominal: Género y número”. En Gramática descriptiva de la Lengua Española, dirigida por Ignacio Bosque y Violeta Demonte, tomo 3, 4843-4913. Madrid: Espasa Calpe.

» Fábregas, Antonio. 2013. La morfología: El análisis de la palabra compleja. Madrid: Síntesis.

»Felíu Arquiola, Elena. 2009. "Palabras con estructura interna”. En Panorama de la lexicología, editado por Elena de Miguel Aparicio, 51-82. Barcelona: Ariel.

» Lang, Mervyn F. 1992. Formación de palabras en español. Madrid: Cátedra.

» Lliteras Poncel, Margarita. 2008. “Del género derivativo al género flexivo”. En GrammaTemas 3: España y Portugal en la tradición gramatical, editado por Marina Maquieira Rodríguez y María Dolores Martínez Gavilán, 125-148. León: Universidad de León.

» Lüdtke, Jens. 2011. La formación de palabras en las lenguas románicas: su semántica en diacronía y sincronía. México, D. F.: El Colegio de México.

» Menéndez Pidal, Ramón. 1918. Manual de gramática histórica española. Madrid: Victoriano Suárez.

» Miranda, José Alberto. 1994. La formación de palabras en español. Salamanca: Ediciones Colegio de España.

» Nebrija, Elio Antonio de. 1989 [1492]. Gramática de la lengua castellana. Madrid: Editorial Centro de Estudios Ramón Areces.

» Pena, Jesús. 1999. “Partes de la morfología: Las unidades del análisis morfológico”. En Gramática descriptiva de la lengua española, dirigida por Ignacio Bosque y Violeta Demonte, tomo 3, 4305-4366. Madrid: Espasa Calpe.

» Rainer, Franz. 1993. Spanische Wortbildungslehre. Tübingen: Max Niemeyer Verlag.

»Real Academia Española. 2017. Diccionario de la lengua española. Edición del Tricentenario. Actualización 2017. En línea: https://dle.rae.es/. Fecha de consulta, 23 de marzo de 2018.

»Real Academia Española y Asociación de Academias de la Lengua Española. 2009. Nueva gramática de la lengua española. Madrid: Espasa Libros.

»Santiago Lacuesta, Ramón y Eugenio Bustos Gisbert. 1999. “La derivación nominal”. En Gramática descriptiva de la lengua española, dirigida por Ignacio Bosque y Violeta Demonte, 4505-4594. Madrid: Espasa Calpe.

» Serrano-Dolader, David. 1994. “Notas a propósito de los sustantivos verbales rizotónicos con sufijo cero en español”. Romanistisches Jahrbuch 44: 282-290.

» Serrano-Dolader, David. 2010. “El género en los sustantivos: ¿flexión y/o derivación?”. En La gramática del sentido: léxico y sintaxis en la encrucijada, editado por José Fran- 
cisco Val Álvaro y María del Carmen Horno Chéliz, 249-270. Zaragoza: PUZ. Versión electrónica del autor: 1-20. Fecha de consulta, 20 de marzo de 2018. < https://www. academia.edu/3068594/El_g\%C3\%Agnero_en_los_sustantivos_flexi\%C3\%B3n_y_o_ derivaci\% $\mathrm{C}_{3} \% \mathrm{~B}_{3} \mathrm{n}>$.

» Stehlík, Petr. 2016. Problém delimitace některých slovotvorných postupů a prostředků ve španělštině. Brno: Masarykova univerzita.

»Stehlík, Petr. 2017. “La sufijación apreciativa: ¿de verdad a medio camino entre la morfología derivativa y la flexiva?”. En Procesos morfológicos: Zonas de interferencia, editado por Jesús Pena, 177-189. Santiago de Compostela: Universidade de Santiago de Compostela.

»Varela Ortega, Soledad. 1988. “Flexión y derivación en la morfología léxica”. En Homenaje a Alonso Zamora Vicente, volumen 1, 511-524. Madrid: Castalia.

»Varela Ortega, Soledad. 1990. Fundamentos de morfología. Madrid: Síntesis.

»Varela Ortega, Soledad. 2005. Morfología léxica: La formación de palabras. Madrid: Gredos. 